\title{
Giulio Magli, Heavens and Earth in Ancient China: Sacred Landscapes of Imperial China
}

Cham, Switzerland: Springer Nature, 2020. Hardback, i-vii, 179 pp., illus. ISBN 978-3-030-49323-3. £27.99.

\section{David W. Pankenier}

Lehigh University, United States

dwp0@lehigh.edu

This richly illustrated new book by Giulio Magli is a welcome addition to his important studies of archaeoastronomy (see for example, Mysteries and Discoveries of Archaeoastronomy: From Giza to Easter Island, 2009), in the form of a specialised monograph on the siting of Chinese monumental mortuary architecture in the landscape from earliest times to the end of the imperial period. Giulio Magli is Professor in the Department of Mathematics at the Politecnico di Milano, Italy, and has travelled extensively in China in order to produce this book. He is the author or co-author of a series of highly readable books that provide excellent introductions to the application of the methods of archaeoastronomy to the study of monuments, temples and other high-value architecture in various locations worldwide. In this new book, Magli has adopted the methods of cognitive archaeology in interpreting the application of the uniquely Chinese principles of fengshui (geomancy) as applied to the siting and construction of the monumental tomb complexes of imperial China from the late third-century $B C$ through to the early nineteenth century $A D$.

As the author states (p. 17):

Cognitive Archaeology is an approach focusing on the material relics of the human past, which aims to describe them as objects that had their primary cultural existence as "percepts" in topological relation to one another. They thus fitted the cognitive schemes of their creators, and can be fully understood - that is, not only "functionally" understood - only if such schemes are also studied and, at least as far as possible, understood as well.

In this respect, the book is intended to bridge the epistemological gap between the largely functional approach of traditional archaeoastronomy and the ethnographically informed approaches of cultural astronomy. The Chinese case is uniquely suited in 
this regard because of the vast documentary resources available to the researcher, by comparison with ancient Egypt, Mesopotamia, or Mesoamerica, for example.

After a very brief general introduction to ancient Chinese cosmological concepts and intellectual history for general readers, the following seven chapters examine in great detail the siting of the imperial mortuary complexes from the unification of China by the First Emperor of Qin in $221 \mathrm{BC}$ through to the layout of the imperial tombs of the final Qing (Manchu) Dynasty that was deposed in AD 1911. Obviously, given the 2000year timespan covered by this study the author's discussion is of necessity focused and specialised in taking up the principles of fengshui as applied to the siting of monumental structures in the landscape. In the process, the author puts paid to the notion that the magnetic compass was used with a view to achieving greater precision, except in a crude way using the so-called luopan, or geomancer's "compass".

With the exception of the imperial capital of the Ming Dynasty, the Vermilion Forbidden City in the heart of present-day Beijing, the reader will not find here any discussion of the application of the principles of geomancy to the design and siting of towns and villages, temples, abbeys, shrines, paths for contemplation (especially in the mountainous landscape), lakes and so on, so often depicted in Chinese landscape painting. The deservedly famous aesthetics of such architectural elements has been the subject of other studies which offer a fuller picture of what geomantic siting in diverse locations was all about. The author's summation is apt, however:

The sacred landscapes of imperial China we have come across in this book are outstanding examples of how deep and harmonious the relationship between the human-built environment and natural settings can be. [...] In Feng Shui, the "object" landscape turns out to be a sort of living entity, which is endowed with features which can add up to a increasing coefficient of auspiciousness, or sacredness. (pp. 151, 152).

This brings me to a couple of quibbles about the presentation of some Chinese concepts. Magli states that the Chinese canonical works are "Classics, a series of texts credited directly to Confucius" (p. 3). This is strictly true of only a couple, the Analects of Confucius and the Springs and Autumns Annals, and even the latter attribution is dubious. Further, "[s] hamanistic functions can be the duties of specialized figures, or can coincide with the divine powers of the rulers themselves, as in China" (p. 11); but as stated, the author's characterisation could well apply to any revered individual charged with communicating with the divine, even the Pope. Typically associated with animal familiars, shape-shifting and communication with the supra-visible, often by means of psychoactive substances, shamanism basically refers to spiritual practices such as those among, for example, the indigenous tribes of northern Siberia and North America. In the case of the rulers of China, for the second millennium AD the characterisation is inappropriate.

Elsewhere (p. 26), after a brief reference to the mythical initiator of Chinese civilisation, the Yellow Emperor Huangdi, the author states that "the name Huangdi was adopted by the First Emperor of Qin, and his cult further developed during the Han, who were searching for an ancestral icon of centralized power" (p. 26). This is a confusion of huang "yellow" with homophone huang "august", so that Qin shi huangdi actually means "First August Emperor of Qin", and not "First Yellow Emperor of Qin". 
More significantly, in discussing the Chinese concept of $q i(p .4)$, the author states that "Qi is an interior spirit of individuals". This statement is in need of serious qualification, as a proper understanding of qi bears importantly on the conceptual basis underlying fengshui and notions of harmonisation with the cosmos. The author's classical training may have led him to construe qi as a sort of pneuma (spirit or soul). He is certainly not alone in such a misapprehension, because there is nothing in the western conceptual universe (at least before the twentieth century) that truly resembles qi, except perhaps in quantum mechanics. Qi is not "spirit" per se but a combination of spirit and matter that might be described as materia vitalis. Materiality is inseparable from spirit, so no mindbody duality. Qi is, at one and the same time, the stuff of which all things are composed as well as the animating impulse inherent in all things, not just the living. So, qi runs the gamut from the solid and inert like rock, to the fluidity of water, to the volatility of fire or gas, to the ethereal essence of space. All living and non-living things, including humans and the spirits of the dead, are situated somewhere in the middle of the spectrum. It is for this reason that a disturbance anywhere in the "motive fabric" of universal qi can propagate throughout and destabilise the homeostasis of yin and yang so crucial to the maintenance of regularity and harmony in the world. This is the concept that Carl Jung dubbed "synchronicity".

Lastly, I am troubled by the author's consistent reference to the imperial mortuary tumuli as "pyramids". This is a misnomer, as the resemblance is only superficial. Pyramids make no secret of the fact that they are man-made, with the essential impulse being a reaching for oneness with the supra-visible spiritual essence on high. In the Chinese case, tumuli ling (as in shanling "mountains and hills") in the first instance, means "hill" and not "tomb" (p. 52), although in time, from conventional usage ling acquired that specialised meaning. The basic idea was to create a simulacrum of the world within which a palace (in the case of nobility) was built to house the corporeal remains of the body po, while the spirit-essence hun made its way to the other realm. The basic idea was to mimic and encapsulate heaven and earth. This is why in the early and medieval period the domed ceilings of burial chambers were often decorated (as in Egypt) with representations of the starry sky. But, in contrast to Egypt or Mesoamerica, the tumuli were sometimes wooded, or alternatively shrubbery was allowed to grow wild on them to resemble mountains. Inside, the structure may have included the layering of rammed earth or blocks to support the weight above and to prevent landslides, but the exterior was always covered with a thick layer of earth so as to make it resemble a natural part of the landscape, albeit oriented to harmonise with the topography. Massive tumuli also served the eminently practical purpose of discouraging plundering. In my view, therefore, when the author refers to an "age of the pyramids" (p. 51) for the early imperial period, and "from pyramids to mountains" (p. 75) in reference to the subsequent model, he is creating a false dichotomy. The impulse was the same throughout even if the monumental realisation changed. On the whole, however, considering the amount of ground he covers, Magli's discussion is commendably accurate and well-documented.

The text is richly illustrated and followed by an appendix with sections that provide useful technical tools for the uninitiated: the azimuth-altitude reference system, the 
horizon formula, the use of virtual globe software and paleo-magnetic models. This is followed by a table of all relevant data points with regard to the mortuary monuments, their dimensions and placement. The references are extensive and helpful in pointing the way to further study. This is a very good book for readers interested in monumental architecture in general, in geomancy in specific and in cognitive archaeology in the service of cultural astronomy and the siting of sacred sites in the landscape.

Table 1 notes some errata, including instances where an author's given name has been cited as the family name.

TABLE 1. Errata for Magli, Heavens and Earth in Ancient China, compiled by reviewer.

\begin{tabular}{|c|c|c|}
\hline Page or figure no. & Error & Correction \\
\hline 2 & Nuwa & Nüwa \\
\hline 4 & carapace & plastron \\
\hline 11 and passim & cosmization & cosmicization \\
\hline 24 & Shixi & shi"cosmograph" \\
\hline 34 & Xianjang & Xianyang \\
\hline 39,46 & Guolong 2005 & Lai 2005 \\
\hline 48 & shear & sheer \\
\hline 52 & -ling & not "tomb", but tumulus \\
\hline 53 & Empress Lu & Empress Lü \\
\hline 54 fig. $4.3,56$ & Empress Lou & Empress Lü \\
\hline \multirow[t]{3}{*}{56} & Nanfeng 2013 & Jiao 2013 \\
\hline & Wuzhan 2011 & Yang 2011 \\
\hline & Chongwen 2007 & Gao 2007 \\
\hline $47,70,71$ & Huo Qibing/Ho Qubing & Huo Qubing \\
\hline 85 & Kuangyn & Kuangyin \\
\hline $131,132,136,140,141,163$ & Shunzi & Shunzhi \\
\hline 135 & Kanji & Kangxi \\
\hline 141 & Yonghzen & Yongzheng \\
\hline 143 & Duaogong & Daoguang \\
\hline \multirow[t]{12}{*}{ 172-179 (References) } & Chang Y, Li T & Yong $\mathrm{C}$, Tong L \\
\hline & Chongwen G & Gao C \\
\hline & Guo Qinghua & Guo Q \\
\hline & Guolong L & Lai G \\
\hline & Hsueh-Man S & Shen $\mathrm{H}$ \\
\hline & Huo W & Wei H \\
\hline & Jie S & Shi J \\
\hline & Grydeho'j & Grydehøj \\
\hline & Nanfeng J & Jiao N \\
\hline & Ping $X$ & XuP \\
\hline & Qingquan L & Li Q, Deng F \\
\hline & Qingzhu L & Liu Q \\
\hline
\end{tabular}




\begin{tabular}{|l|l|l|}
\hline Page or figure no. & Error & Correction \\
\hline \multirow{4}{*}{} & Wan & Wan MCK \\
\cline { 2 - 3 } & Wei C, Weixing Z & Wei C, Zhang W \\
\cline { 2 - 3 } & Wuzhan Y & Yang, W \\
\hline & Xiuzhen L & Li W \\
\cline { 2 - 3 } & Zhewen L & Luo Z \\
\cline { 2 - 3 } & Zhongshu Z & Zhao Z \\
\cline { 2 - 3 } & Zhou H & Zhou X \\
\hline
\end{tabular}

\section{References}

Magli, G., 2009. Mysteries and Discoveries of Archaeoastronomy: From Giza to Easter Island. New York: Copernicus Books. 